\title{
Regiocontroled Pd-catalysed C5-arylation of 3-substituted thiophene derivatives using a bromo-substituent as blocking group
}

\author{
Mariem Brahim ${ }^{1,2}$, Hamed Ben Ammar ${ }^{*}$, Jean-François Soulé ${ }^{* 1}$ and Henri Doucet ${ }^{* 1}$
}

\author{
Full Research Paper \\ Address: \\ ${ }^{1}$ Institut des Sciences Chimiques de Rennes, UMR 6226 \\ CNRS-Université de Rennes "Organométalliques: Matériaux et \\ Catalyse", Campus de Beaulieu, 35042 Rennes, France. Tel.: \\ 00-33-2-23-23-63-84 and 2Laboratoire de Synthèse Organique \\ Asymétrique et Catalyse Homogène, (UR 11ES56) Université de \\ Monastir, Faculté des Sciences de Monastir, avenue de \\ l'environnement, Monastir 5000, Tunisia

\section{Email:} \\ Hamed Ben Ammar ${ }^{*}$ - hamed_benammar@yahoo.fr; \\ Jean-François Soulé* - jean-francois.soule@univ-rennes1.fr; \\ Henri Doucet ${ }^{*}$ - henri.doucet@univ-rennes1.fr \\ * Corresponding author \\ Keywords: \\ aryl bromides; $\mathrm{C}-\mathrm{H}$ bond activation; catalysis; direct arylation; \\ palladium; thiophenes \\ Beilstein J. Org. Chem. 2016, 12, 2197-2203. \\ doi:10.3762/bjoc. 12.210 \\ Received: 25 July 2016 \\ Accepted: 27 September 2016 \\ Published: 17 October 2016 \\ This article is part of the Thematic Series "Green chemistry". \\ Guest Editor: L. Vaccaro \\ (c) 2016 Brahim et al.; licensee Beilstein-Institut. \\ License and terms: see end of document.
}

Open Access

\begin{abstract}
The use of a bromo-substituent as blocking group at the C2-position of 3-substituted thiophenes allows the regioselective introduction of aryl substituents at C5-position via Pd-catalysed direct arylation. With $1 \mathrm{~mol} \%$ of a phosphine-free Pd catalyst, KOAc as the base and DMA as the solvent and various electron-deficient aryl bromides as aryl sources, C5-(hetero)arylated thiophenes were synthesized in moderate to high yields, without cleavage of the thienyl C-Br bond. Moreover, sequential direct thienyl C5-arylation followed by Pd-catalysed direct arylation or Suzuki coupling at the C2-position allows to prepare 2,5-di(hetero)arylated thiophenes bearing two different (hetero)aryl units in only two steps. This method provides a "green" access to arylated thiophene derivatives as it reduces the number of steps to prepare these compounds and also the formation of wastes.
\end{abstract}

\section{Introduction}

Thiophene derivatives bearing aryl substituents are important structures because of their biological and/or physical properties. Among them, 3-substituted 5-arylthiophenes are widely used as building blocks for the synthesis of semi-conductors [1-3].
Therefore, the discovery of more direct and selective procedures for access to 5-arylated 3-substituted thiophene derivatives is an important topic in sustainable chemistry [4]. Stille or Suzuki palladium-catalysed coupling reactions [5-10] are some 
of the most efficient methods for the preparation of 5-arylated 3-substituted thiophenes [11-14]. However, before these coupling reactions can be performed, an organometallic compound must be synthesized. In 1990, Ohta and co-workers described the Pd-catalysed direct arylation of thiophene derivatives by coupling reaction with aryl halides $[15,16]$. This is a highly powerful method for a greener access to a very broad range of arylated thiophenes [17-25]. The method is very attractive in terms of green chemistry, because its major by-products are not metal salts but a base associated to HX, and synthesis of an organometallic derivative can be avoided. However, for C3-substituted thiophenes, arylation generally occurred at the C2-position or gave mixtures of C2- and C5-arylated products [26-33]. The introduction of blocking groups at $\mathrm{C} 2$-position on thiophene derivatives in order to arylate regiospecifically the C5-positions had been reported (Figure 1).

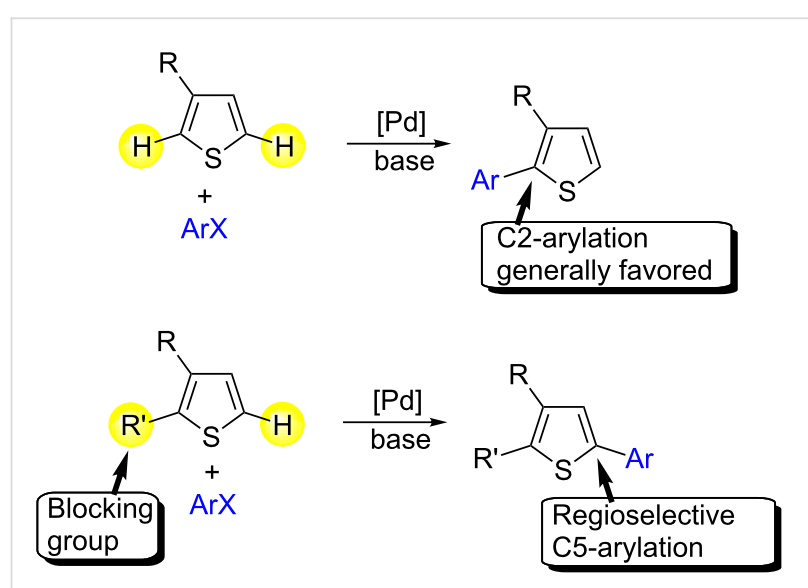

Figure 1: Regioselectivity of the arylation of 3-substituted thiophenes.

In 2010, Fagnou et al. attached a 2-chloro-substituent to the thiophene ring to selectively perform a Pd-catalysed direct arylation of 3-hexylthiophene at the C5-position (Scheme 1, top) [34]. An ester moiety as blocking group at the C2-position of 3-substituted thiophene could also direct regioselectivity of Pd-catalysed direct arylation to the C5-position (Scheme 1, middle) [35]. Mori et al. also reported two examples of C5-arylation of 2-bromo-3-methylthiophene with aryl iodides as aryl sources with $5 \mathrm{~mol} \% \mathrm{PdCl}_{2}\left(\mathrm{PPh}_{3}\right)_{2}$ catalyst and $\mathrm{AgNO}_{3}-\mathrm{KF}$ as the base in DMSO (Scheme 1, bottom) [36].

Herein, we wish to report on green conditions in terms of number of steps, base nature, use of a phosphine-free catalyst at low loading and a quite "atom economic" aryl source promoting such a C5-arylation using C3-substituted 2-bromothiophenes. We report i) that only $1 \mathrm{~mol} \%$ of air-stable $\mathrm{Pd}(\mathrm{OAc})_{2}$ catalyst associated to KOAc promotes the regiospecific access to C5-arylated 2-bromothiophenes without cleavage of the thienyl

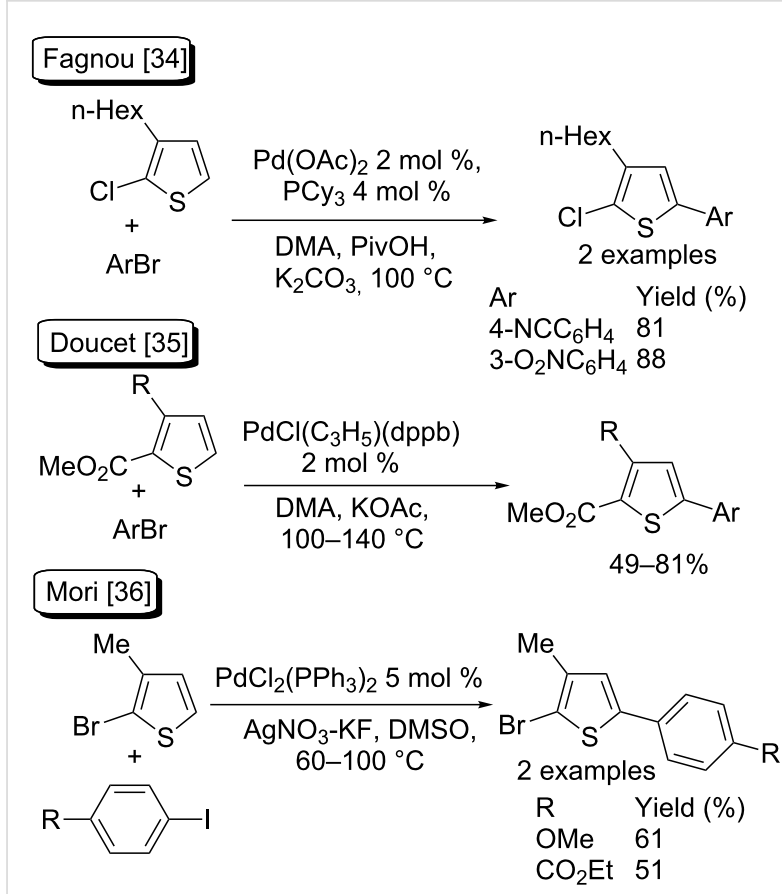

Scheme 1: Blocking groups allowing regioselective C5-arylation of thiophenes.

$\mathrm{C}-\mathrm{Br}$ bond, ii) on the reaction scope using a set of aryl bromides and 2-bromo-3-substituted thiophenes, iii) conditions allowing either the sequential $\mathrm{C} 5$-arylation followed by $\mathrm{C} 2$-arylation or $\mathrm{C} 2$-heteroarylation followed by $\mathrm{C} 5$-arylation of C3-substituted thiophenes.

\section{Results and Discussion}

Based on some of our previous results on Pd-catalysed direct arylation, for this study, DMA and KOAc were selected as the solvent and base [35]. The reaction of 2 equiv of 2-bromothiophene with 1 equiv of 4-bromonitrobenzene using $1 \mathrm{~mol} \%$ of phosphine-free $\mathrm{Pd}(\mathrm{OAc})_{2}$ catalyst performed at $110{ }^{\circ} \mathrm{C}$, only afforded the desired product $\mathbf{1}$ in a trace amount, but a complete conversion of 2-bromothiophene was observed, revealing the high reactivity of the thienyl $\mathrm{C}-\mathrm{Br}$ bond under these conditions (Table 1, entry 1). Using a lower reaction temperature of $80^{\circ} \mathrm{C}$, and a reaction time of $15 \mathrm{~h}$, the desired $\mathrm{C} 5$-arylated product 1 was formed in only $8 \%$ yield due again to the formation of several degradation products (Table 1 , entry 2 ). Then, we examined the influence of the reaction time. After 2 or $4 \mathrm{~h}$, higher yields of 1 ( $55 \%$ and $48 \%$ ) were obtained, respectively; whereas, a very short reaction time of $0.5 \mathrm{~h}$ led to a lower yield of $27 \%$ due to the poor conversion of 4-bromonitrobenzene (Table 1 , entries 3-6). The use of $0.5 \mathrm{~mol} \% \mathrm{Pd}(\mathrm{OAc})_{2}$ catalyst at $80{ }^{\circ} \mathrm{C}$ during $2 \mathrm{~h}$ also afforded 1 in a lower yield of $35 \%$. Again, a large amount of 4-bromonitrobenzene was recovered (Table 1, entry 7). When CsOAc, $\mathrm{NaOAc}$ or $\mathrm{K}_{2} \mathrm{CO}_{3}$ were em- 
ployed as bases instead of KOAc, in the presence of $1 \mathrm{~mol} \%$ $\mathrm{Pd}(\mathrm{OAc})_{2}$ catalyst during $2 \mathrm{~h}$, a partial conversion of 4-bromonitrobenzene was observed and 1 was isolated in $32-40 \%$ yield (Table 1, entries 8-10). It should be noted that in the presence of cyclopentyl methyl ether or diethyl carbonate as solvents, no formation of 1 was observed, and 4-bromonitrobenzene was recovered unreacted (Table 1, entries 11 and 12).

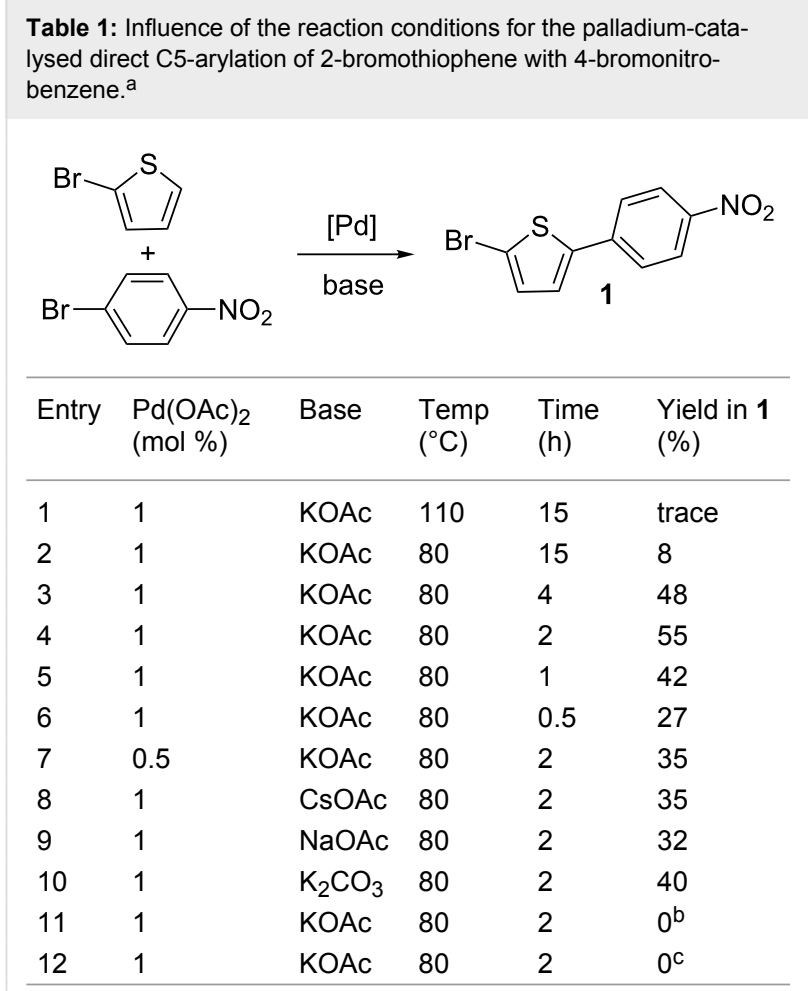

aConditions: $\mathrm{Pd}(\mathrm{OAc})_{2}$, 2-bromothiophene (2 equiv), 4-bromonitrobenzene (1 equiv), base (2 equiv), DMA, isolated yields. ${ }^{\mathrm{b}}$ Cyclopentyl methyl ether as solvent. 'Diethyl carbonate as solvent.

Then, we studied the scope of this reaction using a set of aryl bromides and 2-bromothiophene derivatives, employing the most effective reaction conditions for $\mathrm{C} 5$-arylation of 2-bromothiophene (Table 1, entry 4: $1 \mathrm{~mol} \% \mathrm{Pd}(\mathrm{OAc})_{2}$, DMA,
KOAc, $80{ }^{\circ} \mathrm{C}, 2 \mathrm{~h}$ ) (Schemes 2-4). First, we investigated the reaction of 2-bromothiophene with 4-bromobenzonitrile, 4-bromobenzaldehyde and 4-bromo-2-(trifluoromethyl)nitrobenzene (Scheme 2). The expected coupling products 2-4 were obtained in moderate yields. On the other hand, with 4-bromoanisole as an electron-rich aryl bromide, the desired C5-arylated 2-bromothiophene could not be detected by GC-MS analysis of the crude mixture, and a large amount of unreacted 4-bromoanisole was recovered. Under these reaction conditions, the oxidative addition of 4-bromoanisole to palladium appears to be slower than the oxidative addition of 2-bromothiophene. Therefore, this procedure is limited to the use of electron-deficient aryl bromides. The reactivity of 2-bromofuran with 4-bromonitrobenzene was also investigated. Under the same reaction conditions, $\left(1 \mathrm{~mol} \% \mathrm{Pd}(\mathrm{OAc})_{2}\right.$, DMA, $\mathrm{KOAc}, 80^{\circ} \mathrm{C}, 2 \mathrm{~h}$ ) no formation of the desired 2-bromo-5-arylfuran derivative was observed.

The main interest to tolerate a $\mathrm{C}-\mathrm{Br}$ bond at the $\mathrm{C} 2$-position on thiophene derivatives in the course of such couplings would be the regiospecific access to C5-arylated 3-substituted thiophenes, which cannot be obtained from 2-unsubstituted 3-substituted thiophenes such as 3-methylthiophene. Therefore, a set of aryl bromides was reacted with 2-bromo-3-methylthiophene, under these conditions (Scheme 3). Its reaction with aryl bromides para-substituted by nitro, cyano or formyl substituents gave the desired 5-arylated thiophenes 5-7 in 60-64\% yields, without cleavage of the thienyl $\mathrm{C}-\mathrm{Br}$ bond. Good yields of products $\mathbf{8}$ and 9 were also obtained from the meta-substituted aryl bromides, 3-bromobenzonitrile and 3-bromonitrobenzene. Again, a high yield of $85 \%$ of $\mathbf{1 0}$ was obtained with 4-bromo-2-(trifluoromethyl)nitrobenzene. Then, the reactivity of a set of ortho-substituted aryl bromides was examined. Bromobenzene containing nitro, nitrile or formyl ortho-substituents afforded the C5-arylated thiophenes $\mathbf{1 1 - 1 3}$ in $71-84 \%$ yields. Finally, 3-bromoquinoline and 3-bromopyrimidine were reacted with 2-bromo-3-methylthiophene affording 14 and 15 in 63\% and $66 \%$ yields, respectively. The higher yields obtained for the arylation of 2-bromo-3-methylthiophene than with 2-bromo-

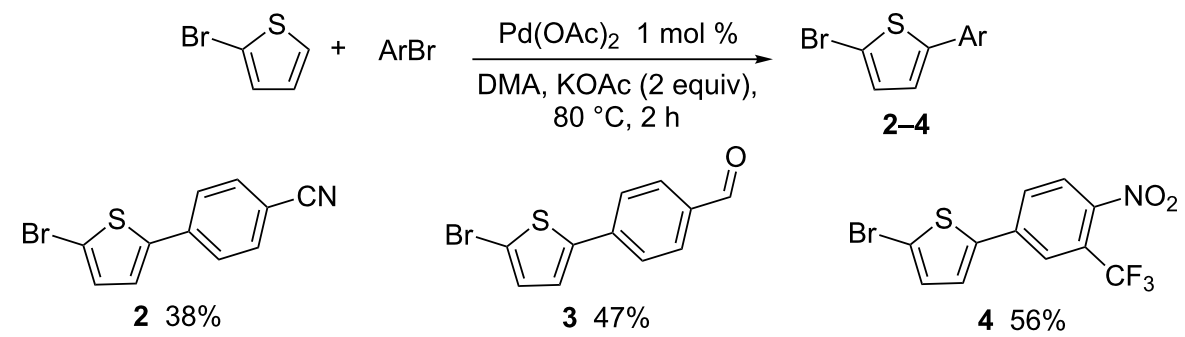


<smiles>CC1=C(Br)S[C+]=C1</smiles>

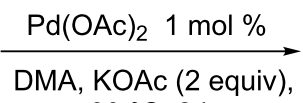
$80^{\circ} \mathrm{C}, 2 \mathrm{~h}$<smiles>Cc1cc(-c2ccc([N+](=O)[O-])cc2)sc1Br</smiles><smiles>Cc1cc(-c2ccc(C#N)cc2)sc1Br</smiles><smiles>Cc1cc(-c2cccc(C#N)c2)sc1Br</smiles><smiles>Cc1cc(-c2cccc([N+](=O)[O-])c2)sc1Br</smiles><smiles>Cc1cc(Br)sc1Br</smiles><smiles>Cc1cc(-c2ccc(C=O)cc2)sc1Br</smiles>

7 63\%<smiles>Cc1cc(-c2ccc([N+](=O)[O-])c(C(F)(F)F)c2)sc1Br</smiles><smiles></smiles><smiles>Cc1cc(-c2ccccc2C#N)sc1Br</smiles><smiles>Cc1cc(-c2ccccc2C=O)sc1Br</smiles><smiles>Cc1cc(-c2cnc3ccccc3c2)sc1Br</smiles><smiles>Cc1cc(-c2cncnc2)sc1Br</smiles>

*: reaction time $10 \mathrm{~h}$<smiles>[R]c1ccsc1Br</smiles>

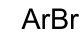

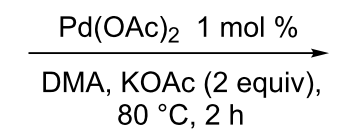<smiles>[R]c1cc(Br)sc1Br</smiles><smiles>CCOC(=O)Cc1cc(-c2ccc([N+](=O)[O-])c(C(F)(F)F)c2)sc1Br</smiles>

$1670 \%$<smiles>CCOC(=O)Cc1cc(-c2ccccc2C#N)sc1Br</smiles><smiles>N#Cc1ccc(-c2cc(Cl)c(Br)s2)cc1</smiles>

$1834 \%$

thiophene are probably due to a slower oxidative addition of 2-bromo-3-methylthiophene to palladium which reduces the formation of side-products.

The reaction is not limited to the use of 2-bromo-3-methylthiophene. A 2-bromothiophene derivative bearing a $\mathrm{CH}_{2} \mathrm{CO}_{2} \mathrm{Et}$ substituent at $\mathrm{C} 3$ also provides regioselectively the desired C5-arylated thiophenes $\mathbf{1 6}$ and $\mathbf{1 7}$ in good yields; whereas, a lower yield of $\mathbf{1 8}$ was obtained for the coupling of 2-bromo-3chlorothiophene with 4-bromobenzonitrile (Scheme 4).
Then, to demonstrate the synthetic potential of the thienyl bromo-substituent, product 1 was coupled with 2-methylthiophene in the presence of $1 \mathrm{~mol} \% \mathrm{Pd}(\mathrm{OAc})_{2}$ catalyst and KOAc as base (Scheme 5). The desired product 19 was obtained in $71 \%$ yield. Under the same conditions, a high yield of $91 \%$ in 20 was obtained from 2 and 2-methyl-4-ethylthiazole. These two reactions demonstrate that the sequential Pd-catalysed direct di-(hetero)arylation, using 2-bromothiophene as central unit, provides a powerful and simple access to non-symmetrically 2,5-di(hetero)arylated thiophene derivatives. 


$$
\text { 年) }
$$

Scheme 5: 5-Heteroarylation of 2-aryl-5-bromothiophenes.

3-Substituted thiophene derivatives containing a heteroaryl unit at the $\mathrm{C} 2$-position and an aryl at $\mathrm{C} 5$ can also be obtained by direct heteroarylation at the $\mathrm{C} 2$-position of the $\mathrm{C} 3$-substituted 2-bromothiophene, followed by direct arylation at $\mathrm{C} 5$ (Scheme 6 and Scheme 7). First, we introduced imidazopyridinyl or thiazolyl groups at C2-position of 2-bromo-3methylthiophene. In the presence of $1 \mathrm{~mol} \% \mathrm{Pd}(\mathrm{OAc})_{2}$ and $\mathrm{KOAc}$ as base at $150{ }^{\circ} \mathrm{C}$ the products $\mathbf{2 1 - 2 3}$ were obtained in $70-88 \%$ yields. In all cases, no C2-arylation of the 2-bromo-3methylthiophene with itself to produce 5'-bromo-3,4'-dimethyl2,2'-bithiophene was observed.

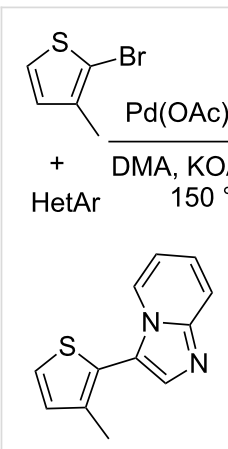

$2170 \%$

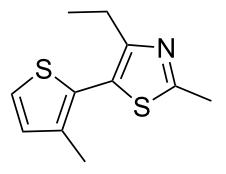

$2288 \%$

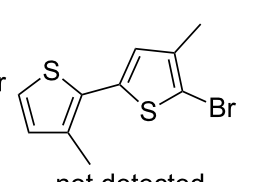

not detected
Scheme 6: 2-Heteroarylation of 2-bromo-3-methylthiophene.

Then, from the C2-heteroarylated 3-methylthiophenes 21-23, a second direct arylation at position C5 allows to prepare the products $\mathbf{2 4 - 2 6}$ in $87-91 \%$ yields (Scheme 7).

The synthesis of 3-substituted thiophenes derivatives containing two different aryl groups at C2 and C5 positions via Suzuki coupling in the second step was also attempted (Scheme 8). The reaction of $\mathbf{5}$ with phenylboronic acid in the presence of only $1 \mathrm{~mol} \% \mathrm{Pd}(\mathrm{OAc})_{2}$ catalyst and $\mathrm{K}_{2} \mathrm{CO}_{3}$ as base gave 3-methyl5-(4-nitrophenyl)-2-phenylthiophene (27) in $60 \%$ yield. A higher yield of $80 \%$ in $\mathbf{2 8}$ was obtained for the coupling of $\mathbf{1 6}$ with phenylboronic acid.

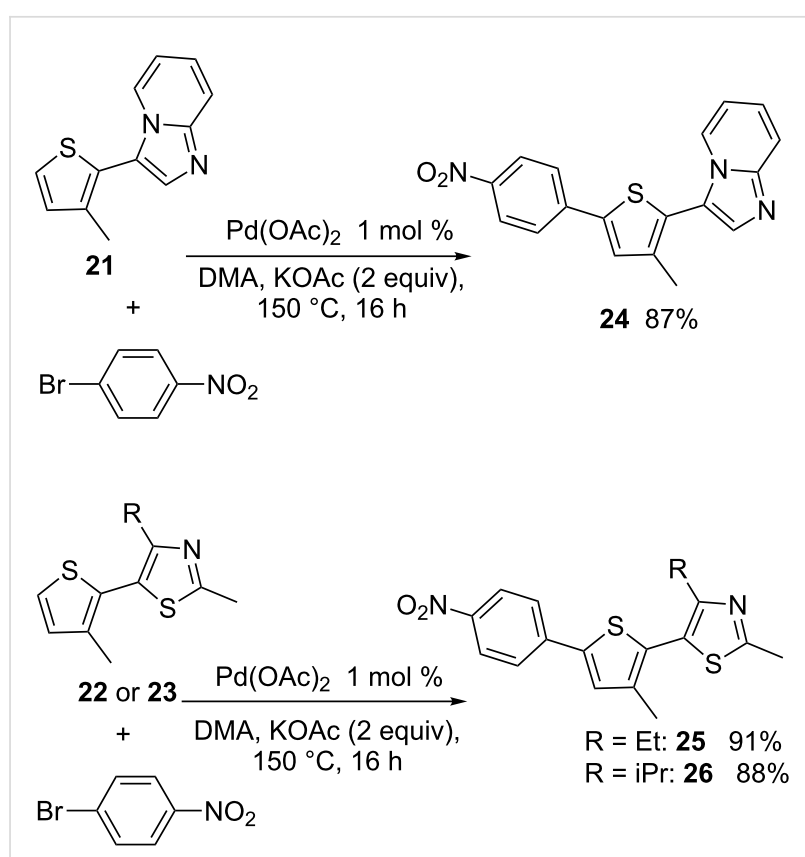

Scheme 7: 5-Arylation of 2,3-disubstituted thiophenes.

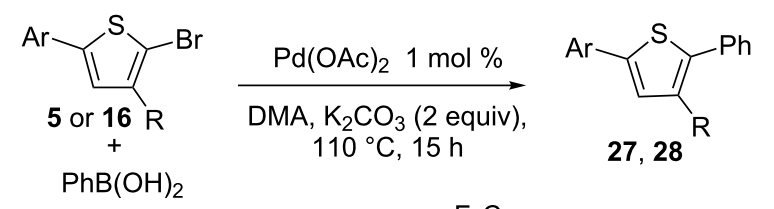<smiles>Cc1cc(-c2ccc([N+](=O)[O-])cc2)sc1-c1ccccc1</smiles>

$2760 \%$<smiles>CCOCc1cc(-c2ccc([N+](=O)[O-])c(C(F)(F)F)c2)sc1-c1ccccc1</smiles>

Scheme 8: 5-Arylation of 2-aryl-5-bromothiophenes.

In order to further demonstrate that a bromo-substituent at C2-position of the thiophenes can be considered as a protecting group, we removed it via palladium-catalysed hydrogenolysis (Scheme 9). Treatment of 14 with $2 \mathrm{~mol} \% \mathrm{Pd} / \mathrm{C} \mathrm{(10 \% )} \mathrm{and} \mathrm{tri-}$ methylamine in ethanol under hydrogen pressure, gave the desired debrominated product $\mathbf{2 9}$ in almost quantitative yield.

\section{Conclusion}

In summary, we report here that the use of a 2-bromo-substituent on thiophenes acts as a blocking group, allowing their regioselective Pd-catalysed C5-arylation even in the presence of aryl bromides as aryl sources. Only $1 \mathrm{~mol} \%$ of phosphine-free air stable $\mathrm{Pd}(\mathrm{OAc})_{2}$ catalyst in the presence of KOAc as base promotes the $\mathrm{C} 5$-arylation of 2-bromothiophenes containing various C3-substituents with electron-deficient (hetero)aryl bro- 


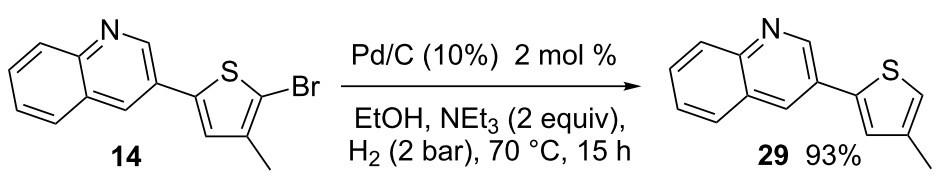

Scheme 9: Deprotection of 2-aryl-5-bromothiophene 14.

mides. The sequential direct C5-arylation of 2-bromothiophenes followed either by a Suzuki coupling or a second direct arylation was found to allow the preparation of 2,5di(hetero)arylated thiophenes bearing two different (hetero)aryl units. This method provides a convenient "greener" access to arylated thiophene derivatives as 1) it reduces the number of steps to prepare these compounds, 2) it employs the easily available $\mathrm{Pd}(\mathrm{OAc})_{2}$ catalyst and aryl bromides as aryl sources, and the inexpensive base KOAc, 3) it reduces the formation of wastes.

\section{Supporting Information}

\section{Supporting Information File 1}

Procedures, ${ }^{1} \mathrm{H}$ and ${ }^{13} \mathrm{C}$ NMR data of all compounds.

[http://www.beilstein-journals.org/bjoc/content/

supplementary/1860-5397-12-210-S1.pdf]

\section{Acknowledgments}

We thank the Centre National de la Recherche Scientifique, "Rennes Metropole", "UTIQUE" and Scientific Ministry of Higher Education Research of Tunisia for providing financial support.

\section{References}

1. Crouch, D. J.; Skabara, P. J.; Lohr, J. E.; McDouall, J. J. W.; Heeney, M.; McCulloch, I.; Sparrowe, D.; Shkunov, M.; Coles, S. J.; Horton, P. N.; Hursthouse, M. B. Chem. Mater. 2005, 17, 6567-6578. doi:10.1021/cm051563i

2. Li, J.; Qiao, X.; Xiong, Y.; Li, H.; Zhu, D. Chem. Mater. 2014, 26, 5782-5788. doi:10.1021/cm502952u

3. Kim, H. G.; Kang, B.; Ko, H.; Lee, J.; Shin, J.; Cho, K. Chem. Mater. 2015, 27, 829-838. doi:10.1021/cm503864u

4. Li, C.-J.; Trost, B. M. Proc. Natl. Acad. Sci. U. S. A. 2008, 105, 13197-13202. doi:10.1073/pnas.0804348105

5. Li, J. J.; Gribble, G. W. Palladium in Heterocyclic Chemistry; Pergamon: Amsterdam, 2000.

6. Handbook of Organopalladium Chemistry for Organic Synthesis; Negishi, E., Ed.; Part III; Wiley-Interscience: New York, 2002; pp 213 ff.

7. Ackermann, L. In Modern arylation methods; Ackermann, L., Ed.; Wiley Online Library, 2009.

8. Brodnik, H.; Požgan, F.; Štefane, B. Org. Biomol. Chem. 2016, 14, 1969-1981. doi:10.1039/С5ОВ02364E
9. Tùng, Đ. T.; Tuân, Đ. T.; Rasool, N.; Villinger, A.; Reinke, H.; Fischer, C.; Langer, P. Adv. Synth. Catal. 2009, 351, 1595-1609. doi:10.1002/adsc.200900044

10. Toguem, S.-M. T.; Villinger, A.; Langer, P. Synlett 2010, 909-912. doi:10.1055/s-0029-1219380

11. Hayashi, S.; Koizumi, T. Angew. Chem., Int. Ed. 2016, 55, 2701-2704. doi:10.1002/anie.201509319

12. Hung, W.-I.; Liao, Y.-Y.; Lee, T.-H.; Ting, Y.-C.; Ni, J.-S.; Kao, W.-S.; Lin, J. T.; Wei, T.-C.; Yen, Y.-S. Chem. Commun. 2015, 51, 2152-2155. doi:10.1039/C4CC09294E

13. Lincker, F.; Attias, A.-J.; Mathevet, F.; Heinrich, B.; Donnio, B.; Fave, J.-L.; Rannou, P.; Demadrille, R. Chem. Commun. 2012, 48, 3209-3211. doi:10.1039/c2cc17276c

14. Pei, J.; Ni, J.; Zhou, X.-H.; Cao, X.-Y.; Lai, Y.-H. J. Org. Chem. 2002, 67, 4924-4936. doi:10.1021/jo011146z

15. Ohta, A.; Akita, Y.; Ohkuwa, T.; Chiba, M.; Fukunaga, R.; Miyafuji, A.; Nakata, T.; Tani, N.; Aoyagi, Y. Heterocycles 1990, 31, 1951-1958. doi:10.3987/COM-90-5467

16. Aoyagi, Y.; Inoue, A.; Koizumi, I.; Hashimoto, R.; Tokunaga, K.; Gohma, K.; Komatsu, J.; Sekine, K.; Miyafuji, A.; Kunoh, J.; Honma, R.; Akita, Y.; Ohta, A. Heterocycles 1992, 33, 257-272. doi:10.3987/COM-91-S29

17. Li, B.-J.; Yang, S.-D.; Shi, Z.-J. Synlett 2008, 949-957. doi:10.1055/s-2008-1042907

18. Roger, J.; Gottumukkala, A. L.; Doucet, H. ChemCatChem 2010, 2 , 20-40. doi:10.1002/cctc.200900074

19. Ackermann, L.; Vincente, R.; Kapdi, A. R. Angew. Chem., Int. Ed. 2009, 48, 9792-9826. doi:10.1002/anie.200902996

20. Bellina, F.; Rossi, R. Tetrahedron 2009, 65, 10269-10310. doi:10.1016/j.tet.2009.10.015

21. Wencel-Delord, J.; Glorius, F. Nat. Chem. 2013, 5, 369-375. doi:10.1038/nchem.1607

22. Kuzhushkov, S. I.; Potukuchi, H. K.; Ackermann, L. Catal. Sci. Technol. 2013, 3, 562-571. doi:10.1039/C2CY20505J

23. Rossi, R.; Bellina, F.; Lessi, M.; Manzini, C. Adv. Synth. Catal. 2014, 356, 17-117. doi:10.1002/adsc.201300922

24. Yadav, M. R.; Rit, R. K.; Shankar, M.; Sahoo, A. K. Asian J. Org. Chem. 2015, 4, 846-864. doi:10.1002/ajoc.201500105

25. Bheeter, C. B.; Chen, L.; Soulé, J.-F.; Doucet, H. Catal. Sci. Technol. 2016, 6, 2005-2049. doi:10.1039/C5CY02095F

26. Lavenot, L.; Gozzi, C.; Ilg, K.; Orlova, I.; Penalva, V.; Lemaire, M. J. Organomet. Chem. 1998, 567, 49-55. doi:10.1016/S0022-328X(98)00667-6

27. Glover, B.; Harvey, K. A.; Liu, B.; Sharp, M. J.; Tymoschenko, M. F. Org. Lett. 2003, 5, 301-304. doi:10.1021/ol027266q

28. Dong, J. J.; Roy, D.; Jacob Roy, R.; lonita, M.; Doucet, H. Synthesis 2011, 3530-3546. doi:10.1055/s-0030-1260213

29. Chen, L.; Bruneau, C.; Dixneuf, P. H.; Doucet, H. Tetrahedron 2013, 69, 4381-4388. doi:10.1016/j.tet.2012.12.061 
30. Rene, O.; Fagnou, K. Org. Lett. 2010, 12, 2116-2119. doi:10.1021/ol1006136

31. Dong, J. J.; Doucet, H. Eur. J. Org. Chem. 2010, 611-615. doi:10.1002/ejoc.200901213

32. Forgione, P.; Brochu, M.-C.; St-Onge, M.; Thesen, K. H.; Bailey, M. D.; Bilodeau, F. J. Am. Chem. Soc. 2006, 128, 11350-11351. doi:10.1021/ja063511f

33. Borghese, A.; Geldhof, G.; Antoine, L. Tetrahedron Lett. 2006, 47, 9249-9252. doi:10.1016/j.tetlet.2006.10.130

34. Liégault, B.; Petrov, I.; Gorlesky, S. I.; Fagnou, K. J. Org. Chem. 2010, 75, 1047-1060. doi:10.1021/j0902515z

35. Chen, L.; Bruneau, C.; Dixneuf, P. H.; Doucet, H. Green Chem. 2012, 14, 1111-1124. doi:10.1039/c2gc16460d

36. Kobayashi, K.; Sugie, A.; Takahashi, M.; Masui, K.; Mori, A. Org. Lett. 2005, 7, 5083-5085. doi:10.1021/ol052063y

\section{License and Terms}

This is an Open Access article under the terms of the Creative Commons Attribution License

(http://creativecommons.org/licenses/by/4.0), which permits unrestricted use, distribution, and reproduction in any medium, provided the original work is properly cited.

The license is subject to the Beilstein Journal of Organic Chemistry terms and conditions:

(http://www.beilstein-journals.org/bjoc)

The definitive version of this article is the electronic one which can be found at: doi:10.3762/bjoc. 12.210 